\title{
Comparação do Sistema de Monitoramento Computadorizado de Digestão In Vitro com os Métodos In Vivo e In Situ. 2. Uso do Resíduo da Matéria Seca de Forragens ${ }^{1}$
}

\author{
Fábio Prudêncio de Campos ${ }^{2}$, Max Lázaro Vieira Bose ${ }^{3}$, Celso Boin 4 , Dante Pazzanese Duarte \\ Lanna $^{5}$, Jozivaldo Prudêncio Gomes de Morais ${ }^{6}$
}

\begin{abstract}
RESUMO - O objetivo deste trabalho foi comparar o sistema de monitoramento computadorizado da produção de gás in vitro com os métodos in vivo e in situ. Nas comparações, foram utilizadas silagens de milho com alto/baixo teores de matéria seca, com/sem inoculante. A digestibilidade das silagens com alto teor de matéria seca (MS), com/sem inoculação, não apresentou diferenças entre os métodos analisados. Quando avaliadas separadamente do efeito do inóculo, essas silagens diferiram nos métodos in vitro/gás e in situ, mas não no in vivo. Entretanto, quando analisadas somente sob efeito do inoculante, apenas no método in situ houve diferença. Não foram encontradas diferenças na digestibilidade da fibra em detergente neutro (FDN) das silagens com alta ou baixa MS, inoculadas ou não, bem como em relação ao pH ao final da digestão. Em conclusão, o desaparecimento da MS e FDN quantificada pelo resíduo no sistema in vitro/gás foi semelhante aos demais métodos avaliados.
\end{abstract}

Palavras-chave: digestão in vitro, digestão in situ, digestão in vivo, produção de gás, silagem de milho

\section{Comparison of the In Vitro Digestion Computerized Monitoring System with In Vivo and In Situ Methods. 2. Use of the Dry Matter Residue of the Forages}

\begin{abstract}
The objective of this work was to compare the computerized monitoring of the in vitro gas production system with the in vivo and in situ methods. On the comparisons, corn silage with high/low dry matter contents, with/without inoculation, were used. The digestibility of silage with high dry matter (DM) content, with/without inoculation, did not present differences among the analyzed methods. When evaluated apart from the inoculation effect, that silage differed in vitro/gas and in situ methods; however in vivo did not differ. Nevertheless, when analyzed under the inoculation effect, only in in situ method there was no difference. No differences were found on the silage neutral detergent fiber (NDF) digestibility with high or low DM, inoculated or not, as well as in relation to $\mathrm{pH}$ at the end of digestion. In conclusion, the disappearing of DM and NDF determined by the residue of the in vitro/gas system was similar to the others evaluated methods.
\end{abstract}

Key Words: corn silage, gas production, in situ digestion, in vitro digestion, in vivo digestion

\section{Introdução}

As metodologias tradicionais de avaliação nutricional dos alimentos e das necessidades dos animais vêm se complementando com o surgimento de novas técnicas, evoluindo rápido e constantemente. Um exemplo é o novo sistema de avaliação de rações proposto pela Universidade de Cornell, com base em análises mais pormenorizadas do alimento e na fisiologia ruminal, com uso de simulação e predição de produção animal (FOX et al., 1990).

A técnica de digestão in vitro proposta por TILLEY e TERRY (1963) tem sido largamente utilizada para predizer a digestibilidade in vivo. Essa técnica tem por objetivo simular as condições nor- mais do rúmen, com atmosfera anaeróbica, temperatura de incubação constante e $\mathrm{pH}$ ótimo, conforme proposto por WARNER (1956), como rúmen artificial. Nesta técnica, as principais fontes de erros são: quantidade de amostra, tempo de fermentação, infusão de nitrogênio e inóculo, espécie animal, tipo de dieta e $\mathrm{pH}$, além das diferenças entre as marchas analíticas adotadas por diversos laboratórios.

A digestibilidade in vitro da matéria seca é altamente correlacionada com a digestibilidade in vivo (MARTEN e BARNES, 1980). O sistema in vitro é útil para rotina de avaliação de forragens e produz resultados com alta precisão e repetibilidade (BARNES, 1965). Muitos fatores podem influenciar a digestibilidade da MS, incluindo a fonte e a atividade

\footnotetext{
1 Projeto financiado pela FAPESP e pelo CNPq.

2 Zoot./MS - Dados parciais de Dissertação de Mestrado - ESALQ/USP; Doutorando na FCAVJ/UNESP. E.mail: fpcampos_99@yahoo.com

3 Professor aposentado no Departamento de Zootecnia - ESALQ/USP.

${ }^{4}$ Professor aposentado no Departamento de Zootecnia - ESALQ/USP.

${ }^{5}$ Professor no Departamento de Zootecnia - ESALQ/USP. E.mail: dplanna@esalq.usp.br

${ }^{6}$ Professor no Departamento de Biotecnologia Vegetal - UFSCAR. E.mail: jozivald@cca.ufscar.br
} 
do inóculo. Diversos estudos têm indicado que, no método in vitro, a digestibilidade da MS ou da fibra inicia-se na própria forragem, independentemente da fonte de inóculo ruminal (MARINUCCI et al., 1992). Entretanto, outros estudos indicam que há efeitos significativos da fonte de inóculo sobre a digestibilidade da MS (NELSON et al., 1973; GRANT et al., 1974).

CHERNEY et al. (1993), estudando a influência de vacas doadoras e fontes de fibra sobre a digestibilidade in vitro de MS de silagem de milho e de alfafa, com período de incubação de 48 horas, acrescentando solução de extração de NDF (fibra em detergente neutro), concluíram que a fonte de fibra na dieta de vaca doadora de líquido ruminal e o método de filtração do líquido podem afetar a digestibilidade in vitro.

GOERING e VAN SOEST (1970) sugeriram sistemas de análises com base na solubilidade das diferentes frações dos alimentos em soluções detergentes e denominaram o sistema de "somativo". Com o intenso uso desse método, surgiram modificações para aperfeiçoamento da tecnologia (VAN SOEST et al., 1991).

Aspecto importante na avaliação de alimentos é a disponibilidade dos substratos em fornecer energia originada de carboidratos, nitrogênio de fonte protéica e não-protéica (RUSSEL e HESPELL, 1981) em quantidades suficientes para o crescimento e desenvolvimento da flora microbiana, que, por sua vez, proporciona a produção de ácidos graxos voláteis, principal fonte de energia para os ruminantes (CHURCH, 1976).

Têm sido feitos estudos para comparar o método in vitro com o in situ para determinação da digestibilidade dos alimentos. O método in vitro é comumente utilizado pela conveniência, ou quando grande escala de testes de alimentos é requerida (UDÉN, 1992). Entretanto, a acumulação de produtos finais da fermentação e da dieta do animal doador do líquido ruminal pode afetar a digestibilidade in vitro da matéria seca (CHERNEY et al., 1993).

O método in situ é usado rotineiramente para estudar os efeitos do ambiente ruminal (NOCEK, 1988; UDÉN, 1992). MEYER e MACKIE (1986) afirmaram que a freqüência de alimentação do animal hospedeiro e os poros do saco de náilon têm papel importante na interpretação dos resultados, pois, no rúmen, os sacos de náilon são continuamente agitados e comprimidos pelo conteúdo ruminal durante as contrações. Esse mecanismo do rúmen favorece a desobstrução dos poros entupidos dos sacos de nái- lon, por essa ação física ou pressão de gases (MARINUCCI, 1992).

NOCEK et al. (1979) observaram decréscimo na digestibilidade da matéria seca associada à produção e ao acúmulo de gases no saco de náilon.

GRAHAM e AMAN (1984) afirmaram que os métodos in vitro e in situ produziram resultados similares com a cinética da degradação ruminal dos constituintes de palhas.

NELSON et al. (1973), trabalhando com a digestibilidade de cinco forragens (silagem de milho e fenos de alfafa, capim pensacola bahia, capim coastal bermuda e centeio), in situ e in vitro, encontraram diferenças significativas $(\mathrm{P}<0,05)$ entre digestibilidade in situ e in vitro, quando avaliaram os fenos, mas não encontraram diferenças significativos para silagem de milho.

Visando melhor conhecimento das necessidades nutricionais de bovinos e do valor nutritivo de alimentos para arraçoamento mais eficiente, procurou-se testar e comparar o sistema de digestibilidade in vitro computadorizada com utilização de mesmas amostras de alimentos (diversas silagens de milho) utilizadas nos métodos in vivo e in situ, realizados em experimentos anteriores, com o propósito de obter dados para aplicação em cálculos de rações.

\section{Material e Métodos}

Os alimentos utilizados na comparação do sistema de produção de gás in vitro com os métodos in vivo e in situ foram silagens de milho com alto e baixo teores de matéria seca com e sem inoculante. O inoculante utilizado foi o produto comercial " 1174 " da Pioneer Sementes Ltda, contendo Lactobacilus plantarum e Streptococus faecium.

A avaliação da aditivação do inoculante bacteriano sobre a digestibilidade in vivo em bovinos procedeu da seguinte forma: oito bovinos machos castrados da raça Nelore com $350 \mathrm{~kg}$ PV foram adaptados em gaiolas metabólicas. A alimentação foi fornecida duas vezes ao dia. Os animais foram sorteados eqüitativamente nos quatro tipos de silagens, com oito períodos de coletas de sete dias.

$\mathrm{Na}$ avaliação da aditivação do inoculante bacteriano sobre a degradabilidade in situ das silagens inoculadas ou não, foram utilizados três bovinos machos castrados da raça Nelore, fistulados, com peso vivo médio de $600 \mathrm{~kg}$, colocados em gaiolas individuais, onde receberam alimentação e água individualmente. Os três animais foram submetidos aos quatro 
tratamentos (silagem de milho: inoculada com alta MS, não-inoculada com alta MS, inoculada com baixa MS e não-inoculada com baixa MS) durante quatro períodos. Os tempos de incubação no rúmen foram de $3,6,12,24,36,48$ e 72 horas.

As comparações entre os dados de digestibilidade das silagens de milho avaliadas no sistema in vitro/gás e os dados no sistema in situ foram realizadas no tempo 48 horas, nos dois primeiros períodos de avaliação dos alimentos, bem como nos dois períodos no teste in vivo.

A silagem de milho com $41,9 \%$ de MS e $35 \%$ de grãos (PEREIRA, 1995) e o feno de alfafa neste experimento foram apenas considerados como dois alimentos padrões para constatação da eficiência do inóculo (líquido ruminal).

Foram feitas as análises bromatológicas de cada alimento (MS, EE, MM, PB, FDN, FDA, celulose e lignina). Triplicatas de amostras alimentos foram incubadas com líquido ruminal de vacas holandesas e novilhos nelore fistulados no rúmen. Após 48 horas, avaliou-se a digestibilidade in vitro/gás de cada alimento pelo desaparecimento da MS e do FDN pelo resíduo da digestão de cada alimento. Os resultados obtidos foram comparados com os dados obtidos previamente na digestibilidade in vivo e in situ realizada por MORAIS et al. (1996 a, b). O delineamento experimental utilizado foi o inteiramente casualizado, com três repetições por tratamento em esquema fatorial $2 \times 2$ (quatro tratamentos - silagens com alta e baixa MS; inoculadas ou não). Para comparação dos diferentes sistemas, utilizou-se o esquema fatorial $3 \times 4$, para três sistemas (in vitrol gás, in vivo e in situ) e quatro alimentos (silagens com alta e baixa matéria seca inoculadas ou não).

\section{Resultados e Discussão}

Na Tabela 1, são apresentados os valores médios da composição bromatológica dos alimentos utilizados na digestibilidade in vitro/gás, in vivo e in situ.

No sistema in vitro/gás, o feno de alfafa foi utilizado como padrão, considerado alimento ideal para a visualização da eficiência do inóculo utilizado e, conseqüentemente, melhor curva de digestão. $\mathrm{O}$ teor de FDN da silagem de milho, com 41,9\% de MS e $35 \%$ de grãos, está muito abaixo em relação às demais silagens avaliadas. Essa diferença está relacionada com o estádio mais avançado de maturação da planta, por ocasião de sua colheita para ensilagem.

$\mathrm{Na}$ Tabela 2, é mostrada a comparação dos métodos de digestibilidade da MS (desaparecimento da MS) das silagens com alta e baixa matéria seca inoculadas ou não. Foi observado que em cada método de avaliação dos alimentos houve variação pequena, mas significativa. Não foi possível analisar estatisticamente os dados da estimativa da digestibilidade in situ da MS da silagem de milho com 35\% de grãos, pois não havia repetições dos dados originais de experimento anterior. Entretanto, avaliando em termos numéricos, pode-se observar que o método in vitro/gás foi superior na estimativa de digestibilidade da MS dessa silagem (78,3\%), quando comparado ao método in situ $(68,9 \%)$. Essa diferença se deve ao fato de que, no método in vitro/gás, a parte solúvel e insolúvel do alimento está incluída na digestibilidade da MS, enquanto no in situ a parte solúvel foi lavada inicialmente e, portanto, não foi avaliada no processo de digestão.

Comparando os métodos de estimativa da digestibilidade (Tabela 2), pode-se constatar que apenas o sistema in situ apresentou valores significativamente $(\mathrm{P}<0,05)$ superiores em relação aos demais, para a silagem com baixa matéria seca não-inoculada. BLUMMEL e ORSKOV (1993) ressaltam que a extensão e a taxa de degradação de nutrientes dos alimentos baseiam-se no desaparecimento da MS, assumindo, assim, que todas as perdas ocorreram pela fermentação, o que nem sempre acontece. PEARCE et al. (1967) observaram diferentes níveis de fermentação das frações solúveis de palha de trigo, as quais podem ser perdidas no saco de náilon e, conseqüentemente, se superestimar a digestibilidade.

Hanna et al. (1973), citados por THIAGO e GILL (1990), observaram que os microrganismos do rúmen degradam, em primeiro lugar, o parênquima, seguido por floema, células da epiderme e feixes vasculares. Por outro lado, a cutícula que cobre a epiderme e os tecidos lignificados dos feixes vasculares (xilema) não sofrem qualquer degradação, mesmo após 72 horas de fermentação in vitro (Akin et al., 1974 citados por THIAGO e GILL, 1990). Por isto, a digestibilidade in vivo também tem se mostrado mais relacionada com a digestibilidade in vitro do que com qualquer determinação química da parede celular (VAN SOEST et al., 1967).

Nos métodos in vitro/gás e in situ, as estimativas da digestibilidade das silagens de milho com alta ou baixa matéria seca apresentaram-se significativamente diferentes $(\mathrm{P}<0,05)$, quando avaliadas separadamente do efeito do inóculo; já in vivo não houve diferença significativa quanto ao teor de MS (Tabela 3). Analisadas as silagens de milho, independentemente 
Tabela 1 - Composição bromatológica dos alimentos

Table 1 - Chemical composition of the feedstuffs

\begin{tabular}{|c|c|c|c|c|c|c|c|c|c|}
\hline \multirow[b]{2}{*}{$\begin{array}{l}\text { Forragem } \\
\text { Forage }\end{array}$} & \multirow[b]{2}{*}{$\begin{array}{c}\mathrm{MS}(\%) \\
D M\end{array}$} & \multicolumn{8}{|c|}{$\begin{array}{l}\text { Fração (\% na MS) } \\
\text { Fraction (\% in DM) }\end{array}$} \\
\hline & & $\begin{array}{l}\text { FDN } \\
N D F\end{array}$ & $\begin{array}{l}\text { FDA } \\
A D F\end{array}$ & CEL & LIG & $\mathrm{CHO}$ & $\begin{array}{l}\mathrm{PB} \\
C P\end{array}$ & $\mathrm{EE}$ & $\mathrm{MM}$ \\
\hline $\begin{array}{l}\text { Feno de alfafa } \\
\text { Alfalfa hay }\end{array}$ & 87,8 & 33,8 & 25,8 & 21,2 & 5,2 & 33,5 & 20,9 & 3,6 & 8,2 \\
\hline $\begin{array}{l}\text { Alta MS inoculada }{ }^{1} \\
\text { High DM inoculated }\end{array}$ & 37,2 & 61,1 & 35,2 & 28,6 & 6,5 & 24,4 & 7,7 & 1,4 & 5,4 \\
\hline $\begin{array}{l}\text { Baixa MS inoculada } 1 \\
\text { Low DM inoculated }\end{array}$ & 30,3 & 60,3 & 36,4 & 28,9 & 7,5 & 19,6 & 10,2 & 2,8 & 7,1 \\
\hline $\begin{array}{l}\text { Alta MS não-inoculada }{ }^{1} \\
\text { High DM non inoculated }\end{array}$ & 38,4 & 60,5 & 34,5 & 27,5 & 6,9 & 24,7 & 7,6 & 1,6 & 5,6 \\
\hline $\begin{array}{l}\text { Baixa MS não-inoculada }{ }^{1} \\
\text { Low DM non inoculated }\end{array}$ & 29,3 & 58,4 & 34,2 & 27,8 & 6,4 & 23,2 & 9,7 & 2,2 & 6,5 \\
\hline $\begin{array}{l}\text { Silagem de milho } \\
\text { Corn silage }\end{array}$ & 41,9 & 36,5 & 21,6 & 15,4 & 6,3 & 47,4 & 6,6 & 2,6 & 6,9 \\
\hline
\end{tabular}

1 Dados e amostras de silagens obtidos de MORAIS et al. (1996 a,b).

2 Dados e amostras de silagens obtidos de PEREIRA (1995).

1 Data and samples of silages obtained from MORAIS et al. (1996 a,b).

2 Data and samples of solage obtained from PEREIRA (1995).

Tabela 2 - Comparação de dados médios de digestibilidade da matéria seca (MS) de silagem de milho com alta ou baixa MS, inoculada ou não, obtidos pelos métodos de digestão in vitro/gás no período de 48 horas, in situ e in vivo

Table 2 - Comparison of data means of digestibility of dry matter (DM) of corn silage with high or low DM, inoculated or not, obtained by methods of in vitro/gas digestion in the period of 48 hours, in situ and in vivo

\begin{tabular}{lccc}
\hline $\begin{array}{l}\text { Forragem } \\
\text { Forage }\end{array}$ & In vitro $^{1}(\%)$ & In vivo $^{2}(\%)$ & In situ $^{2}(\%)$ \\
\hline $\begin{array}{l}\text { Alta MS inoculada } \\
\text { High DM inoculated } \\
\text { Baixa MS inoculada } \\
\begin{array}{l}\text { Low DM inoculated } \\
\text { Alta MS não inoculada }\end{array}\end{array}$ & $65,0^{\mathrm{bA}}$ & $67,2^{\mathrm{aA}}$ & $66,4^{\mathrm{bA}}$ \\
$\begin{array}{l}\text { High DM non inoculated } \\
\text { Baixa MS não inoculada } \\
\text { Low DM non inoculated }\end{array}$ & $66,6^{\mathrm{aA}}$ & $68,0^{\mathrm{aA}}$ & $67,6^{\mathrm{bA}}$ \\
$\begin{array}{l}\text { Coeficiente de variação (\%) } \\
\text { Coefficient of variation }\end{array}$ & $68,2^{\mathrm{aB}}$ & $65,5^{\mathrm{aA}}$ & $68,9^{\mathrm{aA}}$ \\
\hline $\begin{array}{l}\text { Silagem de milho } \\
\text { Corn silage }\end{array}$ & 3,5 & $65,7^{\mathrm{aB}}$ & $72,3^{\mathrm{aA}}$ \\
\hline
\end{tabular}

Médias seguidas de mesmas letras minúsculas nas colunas e maiúsculas nas linhas não diferem $(P>0,05)$ pelo teste Tukey.

1 Sistema in vitro/gás computadorizado (PELL e SCHOFIELD - 1993).

2 Dados e amostras de silagens obtidos de MORAIS et al. (1996 a,b).

3 Dados e amostra de silagem obtidos de PEREIRA (1995).

Means, followed by the same small letters in the columns and capital letters in the lines, do not differ $(P>.05)$ by Tukey test

1 Computerized in vitro/gas system (PELL e SCHOFIELD - 1993)

2 Data and samples silages obtained from MORAIS et al. (1996 a,b).

3 Data and sample silage obtained from PEREIRA (1995). 
do teor da matéria seca, apenas no método in situ houve diferença significativa $(\mathrm{P}<0,05)$ quanto à inoculação (Tabela 3). Entretanto, para ambos fatores, matéria seca e inoculação, analisadas conjuntamente, a interação se mostrou não significativa.

DANLEY et al. (1973) constataram que o avan- ço da maturidade e a ensilagem afetaram o valor nutritivo das forragens, por intermédio de complexa interação dos constituintes, por alteração de um ou mais de seus componentes simples; esta magnitude dos efeitos é diferente de espécie para espécie de plantas forrageiras.

Tabela 3 - Efeito isolado dos tratamentos na comparação da digestibilidade da matéria seca (MS) de silagem de milho com alta ou baixa MS, com ou sem inoculação, obtida pelos métodos de digestão in vitro/gás, no período de 48 horas, in situ e in vivo

Table 3 - Isolated effect of the treatments in the comparison of dry matter digestibility of (DM) corn silage with high or low MS with or without inoculation, obtained by the methods of in vitro/ gas digestion in the period of 48 hours, in situ and in vivo

\begin{tabular}{|c|c|c|c|}
\hline $\begin{array}{l}\text { Matéria seca } \\
\text { Dry matter }\end{array}$ & In vitro ${ }^{1}(\%)$ & In vivo ${ }^{2}(\%)$ & In situ ${ }^{2}(\%)$ \\
\hline Silagem alta MS & $65,2^{\mathrm{b}}$ & $66,4^{\mathrm{a}}$ & $66,4^{\mathrm{b}}$ \\
\hline $\begin{array}{l}\text { Silage high DM } \\
\text { Silagem baix a MS } \\
\text { Silage low DM }\end{array}$ & $67,4^{\mathrm{a}}$ & $66,9^{\mathrm{a}}$ & $72,3^{\mathrm{a}}$ \\
\hline $\begin{array}{l}\text { Inoculação } \\
\text { Inoculation }\end{array}$ & & & \\
\hline $\begin{array}{l}\text { Silagem inoculada } \\
\text { Silage inoculated }\end{array}$ & $65,8^{\mathrm{a}}$ & $67,6^{\mathrm{a}}$ & $67,0^{\mathrm{b}}$ \\
\hline $\begin{array}{l}\text { Silagem não-inoculada } \\
\text { Silage non inoculated }\end{array}$ & $66,8^{a}$ & $65,6^{\mathrm{a}}$ & $70,6^{\mathrm{a}}$ \\
\hline
\end{tabular}

Médias seguidas de mesmas letras nas colunas não diferem $(P>0,05)$ pelo teste Tukey.

1 Sistema in vitro/gás computadorizado (PELL e SCHOFIELD, 1993).

2 Dados e amostras de silagens obtidos de MORAIS et al. (1996 a,b).

Means, followed by the same letters in the columns, do not differ $(P>.05)$ by Tukey test.

1 In vitro/gas system of computerized (PELL e SCHOFIELD - 1993).

2 Data and samples silages obtained of MORAIS et al. (1996 a,b).

\section{Conclusões}

No método in vitro/gás, o desaparecimento da MS e/ou da FDN quantificada pelo resíduo após digestão está muito próximo dos métodos in vivo e in situ para os alimentos analisados. Contudo, é necessário realizar mais trabalhos, a fim de constatar a eficiência do método com outros tipos de alimentos volumosos ou concentrados, considerando-se que o pH é um fator limitante neste sistema.

\section{Referências Bibliográficas}

BARNES, R.F. 1965. Use of in vitro fermentation techniques for estimating forage digestibility and intake. Agron. J., 57(1):213-216.

BLUMMEL, M., ORSKOV, E.R. 1993. Comparison of in vitro gas production and nylon bag degradability of roughages in predicting feed intake in cattle. Anim. Feed Sci. Technol., 40(3):109-119.
CHERNEY, D.J.R., SICILIANO, J.J., PELL, A.N. 1993. Technical note: forage in vitro dry matter digestibility as influenced by fiber source in the donor cow diet. J. Anim. Sci., 71(5):1335-1338.

CHURCH, D.C. 1976. Digestive physiology and nutrition of ruminants. In: Digestive physiology. 2.ed., Oregon, O.U.S, Bookstores. 349p.

DANLEY, M.M., VETTER, R.L. 1973. Changes in carbohydrate and nitrogen fractions and digestibility of forages: Maturity and ensiling. J. Anim. Sci., 37(4):994-999.

FOX, D.G., SNIFFEN, C.J., O'CONNOR, J.,D., et al. 1990. A model for predicting requirements and feedstuffs utilization. Cornell: The Cornell net carbohydrate and protein system for evaluating cattle diets research. $128 \mathrm{p}$.

GOERING, K.H., VAN SOEST, P.J. 1970. Forage fiber analysis (apparatus, reagents, procedures, and some application), Washington: ARS-USDA, (USDA Agricultural Handbook, n.379).

GRAHAM, H., AMAN, P. 1984. A comparison between degradation of in vitro and in sacco of constituents of untreated and ammonia treated barley straw. Anim. Feed Sci. Technol., 10:199.

GRANT, R.J., MERTENS, D.R. 1990. Impact of forage type, 
corn starch addition and buffer $\mathrm{pH}$ upon in vitro digestion kinetics of neutral detergent fiber. J. Anim. Sci., 68:589-588. (suppl. 1).

GRANT, R.J., VAN SOEST, P.J., McDOWELL, R.E. 1974. Influence of rumen fluid source and fermentation time on in vitro true dry matter digestibility. J. Dairy Sci., 57(2):12011205.

GRANT, R.J., WEIDNER, S.J. 1992. Digestion kinetics of fiber: Influence of in vitro buffer $\mathrm{pH}$ varied within observed physiological range. J. Dairy Sci., 75(2):1060-1068.

MARINUCCI, M.T., DEHORITY, B.A., LOERCH, S.C. 1992. In vitro and in vivo studies of factors affecting digestion of feeds in synthetic fiber bags. J. Anim. Sci., 70(1):296-307.

MARTEN, G.C., BARNES, R.F. 1980. Prediction of energy digestibility of forages with in vitro rumen fermentation and fungal enzymes systems. In: PIGDEN, W.J., BALCH, C.C., GRAHAM, M. (Eds.) Standardization of analytical methodology for feeds. Ottawa: International Development Research. Center, p.61-128.

MEYER, J.H.F., MACKIE, R.I. 1986. Microbiological evaluation of the intraruminal in sacculus digestion technique. Appl. Environ. and Microbiol., 51:622.

MORAIS, J.P.G., BOIN, C., CAMPOS, F.P., et al. Efeito de inoculante bacteriano em silagem de milho quanto a digestibilidade in vivo e fermentação. In: REUNIÃO ANUAL DA SOCIEDADE BRASILEIRA DE ZOOTECNIA, 33, 1996, Fortaleza. Anais... Fortaleza: SBZ, 1996a, p.425-427.

MORAIS, J.P.G., BOIN, C., CAMPOS, F.P. et al. Efeito na degradação in situ e na taxa de passagem de silagem inoculada com aditivo microbiano. In: REUNIÃO ANUAL DA SOCIEDADE BRASILEIRA DE ZOOTECNIA, 33, 1996, Fortaleza. Anais... Fortaleza: SBZ, 1996b, p.428-430.

NELSON, B.D., ELLZEY, H.D., MONTGOMERY, C. et al. 1973. Factors affecting the variability of an in vitro rumen fermentation technique for estimating forage quality. J. Dairy Sci., 55(3):358-366.

NOCEK, J.E. 1988. In situ and other methods to estimate ruminal protein and energy digestibility: A review. J. Dairy Sci., 71(3):2051-2069.

ORSKOV, E.R., MILLS, C.C., ROBINSON, J.J. 1980. The use of whole blood for the protecrion of organic materials from degradation in the rumen. Proc. Nut. Soc., 39:60A.

PEARCE, G.R., SIMPSON, R.G., DOYLE, P.T. Source of variation in the nutrive value of wheat and rice straw. In: WORKSHOP ON PLANT BREEDING AND THE NUTRITIVE VALUE OF THE CROP RESIDUES, Addis Ababa, 1987. Proceedings... Abada: ILCA, 1987. p.195-221.
PELL, A. N., SCHOFIELD, P. 1993. Computerized monitoring of gas production to measure forage digestion in vitro. J. Dairy Sci., 76(4):1063-1073.

PEREIRA, J.R.A. Avaliação das sub-frações dos carboidratos e das proteínas da silagem de milho, farelo de algodão e milho, usando a metodologia do CNCPS e in situ, com bovinos da raça nelore. Piracicaba, SP: ESALQ, 1995. 94p. Dissertação (Mestrado em Agronomia) - Escola Superior de Agricultura "Luiz de Queiroz", Universidade de São Paulo, 1995.

RUSSEL. J.B., HESPELL, R.B. 1981. Microbial rumen fermentation. J. Dairy Sci., 64(6):1153-1169.

THIAGO, L.R.L.S., GILL, M. 1990. Consumo voluntário: fatores relacionados com a degradação e passagem da forragem pelo rúmen. Campo Grande: EMBRAPA, CNPGC. 65p. (EMBRAPA, CNPGC-Documento - 43).

TILLEY, J.M.A., TERRY, R.A. 1963. A two technique for the in vitro digestion of forage crops. J. Br. Grassl. Soc., 18:104111.

UDÉN, P. 1992. The influence of leaf and stem particle size in vitro and of sample size in sacco on neutral detergent fiber fermentation kinetics. Anim. Feed Sci. and Technol., 37:85-94.

VAN SOEST, P.J., WINE, R.H. 1967. Use of detergent in the analysis of fibrous feeds. IV. Determination of plant cell-wall constituents. J. Assoc. Official Analytical Chemists, 50:50-55.

VAREL, V.H., KREIKEMEIER, K.K. 1995. Technical note: comparison of in vitro and in situ digestibility methods. $J$. Anim. Sci., 73(2):578-582.

WAITE, R. 1963. Botanical and chemical changes in maturing grass and their effect on its digestibility. Agron. Progress, 38:50.

WARNER, A.C.I. 1956. Criteria for establishing the validity of in vitro studies with rumen micro-organisms in so-called artificial rumen systems. J. General Microbiol., 14:733-748.

Recebido em: 31/10/97

Aceito em: 27/09/99 